\section{Commentary: Try it, you may like it}

\section{Soichiro Kitamura, MD}

The paper that appeared in the recent issue of the Journal of Thoracic and Cardiovascular Surgery Techniques ${ }^{1}$ reported 4 infants of 3 to 4 months' age who underwent pediatric coronary bypass surgery (PCABS) with an internal thoracic artery (ITA) graft and a surgical microscope. Three of the 4 patients previously had an arterial switch operation (ASO) for transposition of the great arteries. PCABS was performed to restore coronary hypoperfusion due to a failure of coronary transfer, which often leads to perioperative mortality. ${ }^{2,3}$ In their report, the use of a microscope facilitated PCABS for neonates and infants as a reliable mode of surgical treatment, even in emergency situations.

In this scenario, most pediatric cardiac surgeons prefer surgical ostial angioplasty with a patch of various materials rather than PCABS with an ITA, most probably because they are simply not familiar with PCABS. Repair of the transferred coronary orifice by angioplastic procedures requires a total dissection of the suture line for ASO under long aortic crossclamping. PCABS with an ITA graft does not require dissection of previous suture lines at all, which offers much faster and simpler alternatives. Aortic crossclamping is only needed for anastomotic procedures. Retrograde coronary flow by a bypass or saving an ITA for future use is of little concern. The long-term patency and growth potential of the ITA graft in infants and small children who had previously undergone ASO and coronary events are excellent, as shown in Figure 1. They are now free of symptoms, conducting a normal life as a businessman and a student, respectively. Each of the right and left ITAs can provide sufficient blood flow for each of the right and left coronary arteries, and bilateral ITAs can supply entire coronary blood flow to the heart with bilateral coronary obstructions. ${ }^{4}$

From the Japan Cardiovascular Research Foundation, and National Cerebral and Cardiovascular Center, Osaka, Japan.

Disclosures: The author reported no conflicts of interest.

The Journal policy requires editors and reviewers to disclose conflicts of interest and to decline handling or reviewing manuscripts for which they may have a conflict of interest. The editors and reviewers of this article have no conflicts of interest.

Received for publication Aug 27, 2021; revisions received Aug 27, 2021; accepted for publication Sept 1, 2021; available ahead of print Sept 8, 2021.

Address for reprints: Soichiro Kitamura, MD, National Cerebral and Cardiovascular Center, Japan Cardiovascular Research Foundation, 502 Sankus-Ichibankan, Asahimachi, Suita, Osaka 564-0027, Japan (E-mail: skitamur@ncvc.go.jp).

JTCVS Techniques 2021;10:444-5

2666-2507

Copyright (C) 2021 The Author(s). Published by Elsevier Inc. on behalf of The American Association for Thoracic Surgery. This is an open access article under the CC BY-NC-ND license (http://creativecommons.org/licenses/by-nc-nd/4.0/).

https://doi.org/10.1016/j.xjtc.2021.09.013

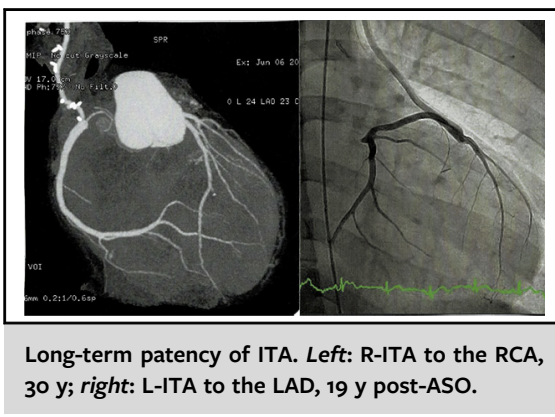

CENTRAL MESSAGE

Pediatric coronary artery bypass surgery using an internal thoracic artery has now been established for infants and children of any age. A surgical microscope facilitates secure anastomosis.

Because of the friability and small size of the coronary artery and the ITA in infants, a microsurgical technique is essential. ${ }^{3,4}$ The use of a surgical microscope facilitates fine anastomosis. Iwata and colleagues are to be commended for demonstrating excellent results with this technique. I myself used a surgical microscope in 1994 for PCABS. ${ }^{4}$ Surgical microscopes have advanced considerably since then. Dr Eishi's group used $\times 20$ magnification and $9-0$ or $10-0$ sutures, which were reasonable under $\times 10$ to 20 magnification. Continuing practice may be necessary to maintain expert hands, although infant coronary bypass is fortunately rare.

Nowadays, brain surgeons, ophthalmologists, ear-nosethroat surgeons, orthopedic surgeons, and plastic surgeons all use microscopes, and lymphatic vessel anastomosis has become possible. Why is this not the case for young pediatric cardiac surgeons? Try it, you may like it. I hope this publication contributes to changing pediatric cardiac surgeons' minds and viewpoints.

The author is grateful to Dr Hiroaki Kawata, Department of Cardiac Surgery, Osaka Women's and Children's Hospital, Osaka, Japan, for allowing him to use the coronary angiogram of the right panel of the Figure 1.

\section{References}

1. Iwata Y, Takeuchi T, Konuma T, Obase K, Eishi K. Infant coronary artery bypass grafting completely under surgical microscope. J Thorac Cardiovasc Surg Tech. 2021;10:441-3.

2. Kitamura S. Pediatric coronary artery bypass surgery for congenital heart disease. Ann Thorac Surg. 2018;106:1570-7.

3. Mavroudis C. Coronary artery bypass grafting in infants, children and young adults for acquired and congenital lesions. Cong Heart Dis. 2017;12:644-6.

4. Kitamura S. A new arena in cardiac surgery. Pediatric coronary artery bypass surgery. Proc Jpn Acad Ser B Phys Biol Sci. 2018;94:1-19. 


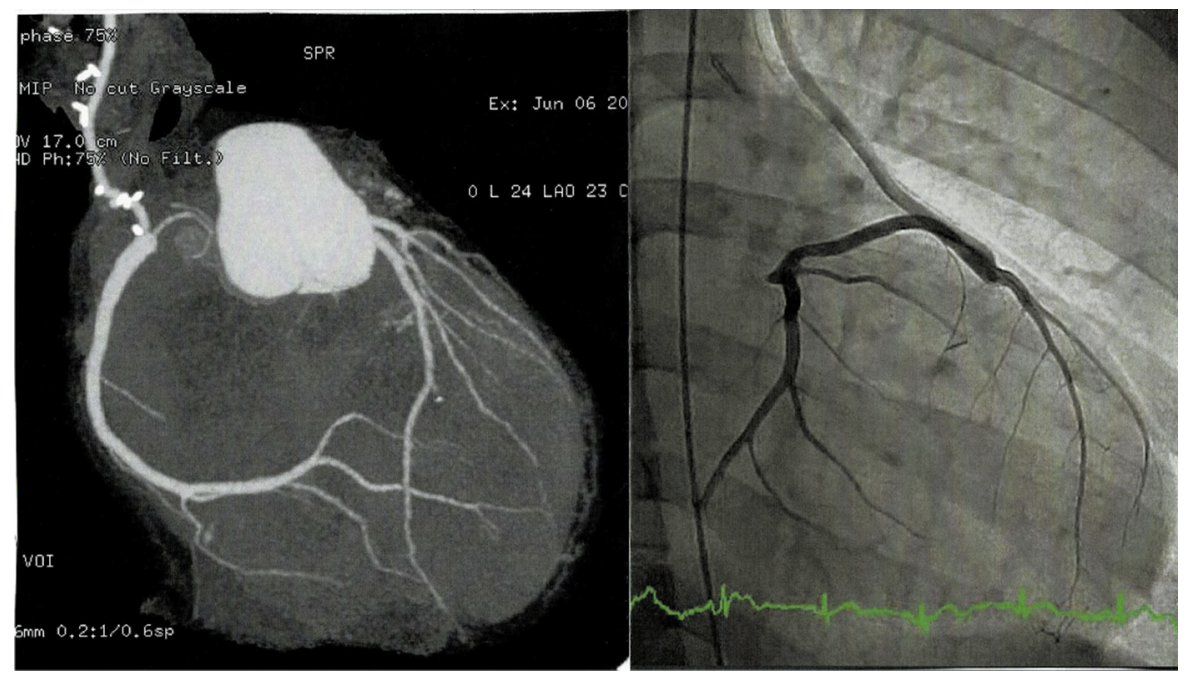

FIGURE 1. Long-term patency of internal thoracic artery (ITA) grafts. Left, Right ITA to the right coronary artery 30 years after ASO for TGA. Right, Left ITA to the left anterior descending artery 19 years after ASO for TGA. ASO, Arterial switch operation; TGA, transposition of the great arteries. 